\title{
Direct oxidation of cyclohexane to adipic acid using nano-gold catalysts
}

\author{
A. Alshammari • A. Köckritz $\cdot$ V. N. Kalevaru • \\ A. Bagabas $\cdot$ A. Martin
}

Received: 28 June 2012/ Accepted: 9 August 2012/Published online: 29 August 2012

(C) The Author(s) 2012. This article is published with open access at Springerlink.com

\begin{abstract}
Adipic acid (AA) is one of the most important commercially available aliphatic dicarboxylic acids, which has a large industrial application in the manufacture of Nylon-6 and Nylon-66. The present work demonstrated a green chemistry route for the direct oxidation of cyclohexane $(\mathrm{CH})$ to AA using supported nano-gold catalyst in one-step reaction. The catalysts were prepared in two steps and were then characterized by different methods such as ICP, BET surface area, XRD, SEM, TEM, etc. Catalytic tests were carried out using Parr autoclave in the temperature range of $100-170{ }^{\circ} \mathrm{C}$, and the products were analyzed by gas chromatograph. Among all investigated catalysts, $\mathrm{TiO}_{2}$ supported nano-gold exhibited the superior activity compared to all other tested catalysts. The conversion of $\mathrm{CH}$ and the selectivity of AA obtained over $\mathrm{TiO}_{2}$ supported catalyst were $16.4 \%$ and ca. $21.6 \%$, respectively, without a noticeable change in the catalyst stability. In summary, it is possible to produce AA with ca. $8 \%$ yield using nanogold supported on $\mathrm{TiO}_{2}$.
\end{abstract}

Keywords Adipic acid · Cyclohexane · Nano-gold · Titanium dioxide
A. Alshammari $(\bowtie) \cdot$ A. Bagabas

National Nanotechnology Research Centre, King Abdulaziz City for Science and Technology, King Abdullah Road,

P.O. Box 6086, Riyadh 11442, Saudi Arabia

e-mail: aalshammari@kacst.edu.sa

A. Köckritz · V. N. Kalevaru · A. Bagabas · A. Martin Leibniz-Institut für Katalyse e.V. an der Universität Rostock, Albert-Einstein-Str. 29a, 18059 Rostock, Germany

\section{Introduction}

The selective oxidation of cyclohexane $(\mathrm{CH})$ to adipic acid (AA) is an industrially important reaction for manufacturing various valuable materials such as polyamides (e.g., nylon 6,6), polyurethanes, polyesters, plasticizers, intermediates for pharmaceuticals and insecticides, etc. [1,2]. AA is also used in medicine and food industry for different applications [3, 4]. The current commercial production process of AA on a commercial scale is made up of two steps. The first step results in a mixture of cyclohexanone and cyclohexanol (i.e., $\mathrm{KA}-\mathrm{K}$ for ketone and $\mathrm{A}$ for alcohol) at around $150{ }^{\circ} \mathrm{C}$ and at $10-20$ bar of air using a cobalt or a manganese catalyst $[2,5]$. KA can also be obtained by phenol hydrogenation, as depicted in Scheme 1. The second step, is an oxidation of KA into AA using nitric acid [6]. This method is environmentally harmful, and it is costly and energy demanding. The generation and liberation of $\mathrm{NO}_{X}$ gases, resulted from the reduction of nitric acid, harm the environment while recycling $>90 \%$ of un-reacted $\mathrm{CH}$ increases the production cost and the energy demand. Therefore, it is a must to develop a novel, environmentally benign for the production of AA.

Besides the commercial process, there are other routes for producing AA. For examples, AA can be obtained by direct oxidation of $\mathrm{CH}$ using hydrogen peroxide, by carbonylation of butadiene, by dimerization of methyl acrylate, or by fermentation of glucose (Scheme 1). In spite of these various routes, the direct oxidation of $\mathrm{CH}$ to $\mathrm{AA}$ in one step using $\mathrm{O}_{2}$, as an oxidant, is indeed an economic and environmentally friendly approach, which is the core of this work.

The use of heterogeneous, solid catalyst in the direct oxidation of $\mathrm{CH}$ to $\mathrm{AA}$ is also known from the prior art. For

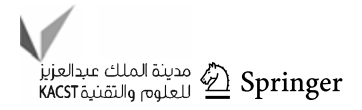


example, iron phthalocyanine encapsulated in $\mathrm{Y}$-zeolite was applied as a catalyst for the direct oxidation of $\mathrm{CH}$ to AA [7]. However, this process strongly suffers from much longer induction periods, i.e., the catalyst requires about $300 \mathrm{~h}$ to reach $\mathrm{CH}$ conversion of ca. $35 \%$ and needs $600 \mathrm{~h}$ to get higher amounts of adipic acid in the product stream, which makes the process commercially unattractive. Furthermore, efforts were also made by various researchers to use gold-based catalysts for the direct oxidation of $\mathrm{CH}$ to AA, but to the best of our knowledge, all such attempts went unsuccessful until now. For instance, various gold catalysts such as Au/graphite, Au/MCM-41 [8], Au/SBA-15, and $\mathrm{SiO}_{2}$ [9] supports were applied for the said reaction, which gave only cyclohexanol and cyclohexanone as major products without any adipic acid in the product stream. Using such catalyst systems, the conversion of $\mathrm{CH}$ was varied in the range from 6 to $20 \%$, but almost no formation of adipic acid was reported. However, the selectivity of both cyclohexanol and cyclohexanone products together were found to be in the range of 17-90\% depending on the catalyst system used and the reaction conditions applied.

On the whole, the catalyst systems used in the prior art are completely different from ours. The goal of the present paper is therefore to provide a direct method for producing AA in a single step with acceptable selectivity from the oxidation of $\mathrm{CH}$ using effective and potential catalyst compositions. The work also aims to supply an easy method for preparing the catalyst and its use in the said oxidation reaction.

\section{Experimental}

\section{Materials}

Tetrachloroauric acid (99\%, Fluka), tri-sodium citrate dehydrate (99.5\%, Fluka), and tannic acid (98\%, Aldrich) were commercially available and were used as received. Commercially available metal oxides were also used. Deionized water $(18.2 \mathrm{M} \Omega \mathrm{cm})$ was obtained from a Milli$\mathrm{Q}$ water purification system (Millipore).

\section{Catalyst preparation}

The preparation of supported gold nanoparticles (AuNPs) on different metal oxides was performed in two steps. The first step involves the preparation of colloidal AuNPs by the reduction of $\mathrm{HAuCl}_{4}(0.15 \mathrm{mmol})$ in aqueous solution using $1 \%$ tannic acid, $1 \%$ sodium citrate, and $\mathrm{K}_{2} \mathrm{CO}_{3}$. The second step involves the impregnation of the colloidal AuNPs with a suitable oxidic support (e.g., $\mathrm{CaO}, \mathrm{MgO}$, $\mathrm{ZrO}_{2}, \mathrm{Al}_{2} \mathrm{O}_{3}$, and $\mathrm{TiO}_{2}$ ). After impregnation (step 2), the slurry was vigorously stirred for $2 \mathrm{~h}$ at room temperature and then the excess solvent was removed on rotary evaporator. The obtained solid was washed three times with water, and then oven dried $120^{\circ} \mathrm{C}$ for $16 \mathrm{~h}$. The dried sample was finally calcined at $350{ }^{\circ} \mathrm{C}$ for $5 \mathrm{~h}$ in air.

\section{Catalyst characterization}

\section{Inductively coupled plasma (ICP)}

ICP results of catalysts were obtained by PERKIN ELMER instrument (model: optima 3000XL), using a microwave pressure digestion (MDS 200; CEM) with hydrofluoric and aquaregia.

\section{Thermal analysis}

Thermogravimetric and differential thermal analysis (TGDTA) were performed with a TG apparatus (Shimadzu TGA-50). Catalysts of about $10 \mathrm{mg}$ were heated from 20 to $900{ }^{\circ} \mathrm{C}$ at a rate of $5{ }^{\circ} \mathrm{C} / \mathrm{min}$ and a flow rate of $25 \mathrm{~mL} / \mathrm{min}$ in air atmosphere.

\section{BET surface area}

BET surface areas (BET-SA) and pore size distribution of the catalysts were obtained on Micrometrics Gemini III2375 instrument by $\mathrm{N}_{2}$ physisorption at $77 \mathrm{~K}$. Prior to the measurements, the known amount of the catalyst was evacuated for $2 \mathrm{~h}$ at $150{ }^{\circ} \mathrm{C}$ to remove physically adsorbed water.

\section{$X$-ray diffraction $(X R D)$}

X-ray diffraction results of the catalysts were recorded on a STADI P (STOE) setup with transmission geometry and equipped with a Ge primary monochromator with $\mathrm{CuK}_{\alpha}$ radiation in the $2 \theta$ ranges from $5^{\circ}$ to $60^{\circ}$ and a positionsensitive detector. The diffraction peaks of the crystalline phase were compared with those standard compounds reported in the JCPDS Date file.

\section{$X$-ray photoelectron spectroscopy (XPS)}

X-ray photoelectron spectroscopy analysis was carried out in an ESCALAB 220iXL spectrometer after exposure the sample to air at room temperature. Measurements were carried out at constant energy of $150 \mathrm{eV}$ (survey), $25 \mathrm{eV}$ (for quantification) and without charge compensation. Monochromatic Al-K $\alpha$ radiation $(1,486.6 \mathrm{eV})$ was applied as the X-ray source. The binding energy scale was calibrated with pure and clean $\mathrm{Cu}, \mathrm{Ag}$, and $\mathrm{Au}$ samples. 
Scheme 1 Summary of the different pathways for AA production

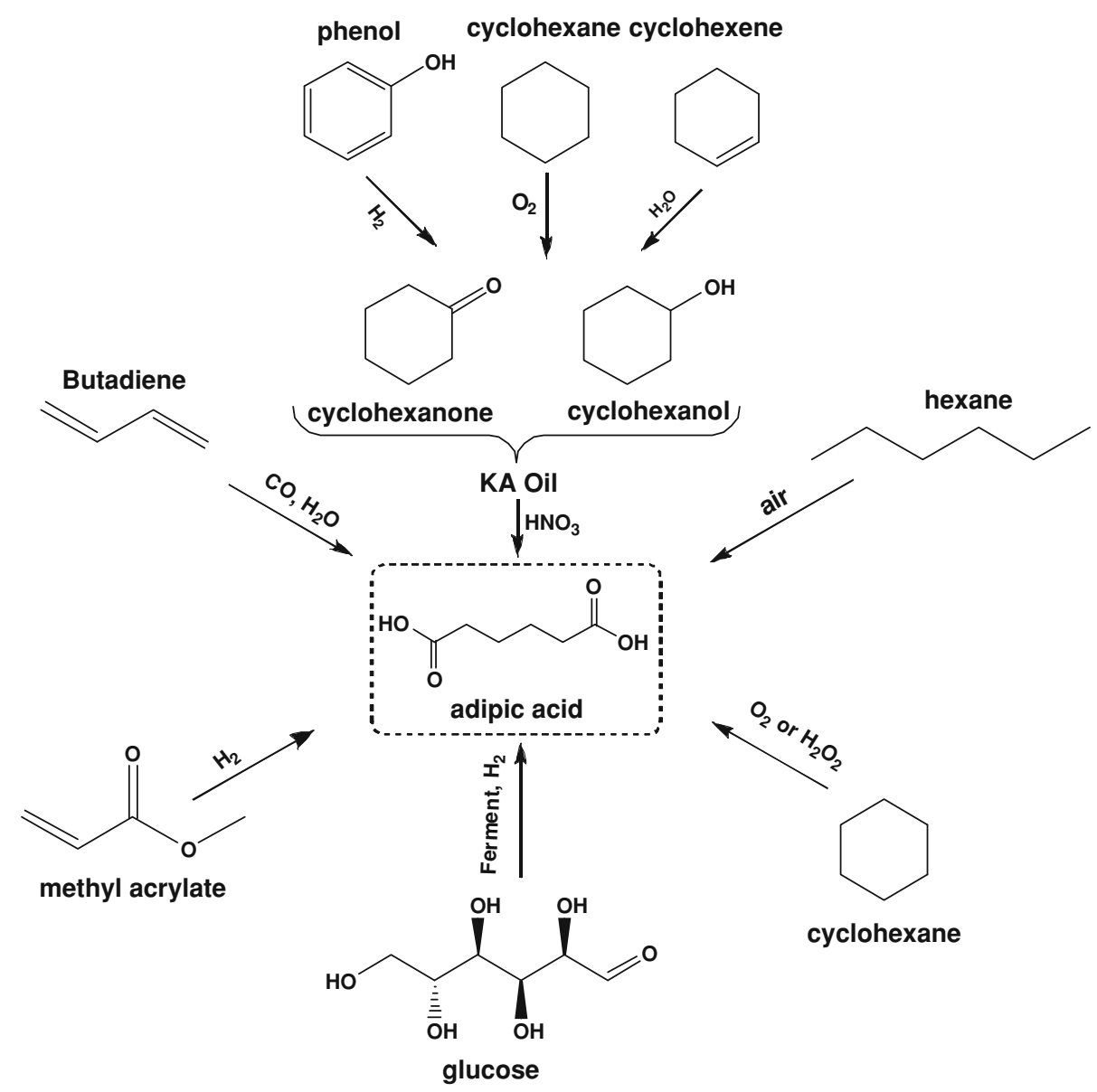

Transmission electron microscopy (TEM)

TEM analysis was carried out using JEM-2100F high-resolution electron microscopy at a voltage of $200 \mathrm{kV}$. Sample preparation of supported AuNPs samples were dispersed in water/methanol and treated with ultrasound for $5 \mathrm{~min}$, and then deposited on a carbon coated grid.

\section{Catalytic measurement}

Activity tests were carried out under pressure using a Parr autoclave $(100 \mathrm{~mL})$ according the procedure described below. In a typical experiment, the reaction mixture consists of $0.3-0.4 \mathrm{~g}$ of supported gold catalyst, $5 \mathrm{~mL}$ of cyclohexane $(\mathrm{CH}), 25 \mathrm{~mL}$ of acetonitrile as solvent, and $0.1 \mathrm{~g}$ of tert-butyl hydroperoxide (TBHP), unless otherwise stated. These components were taken in an autoclave and flushed three times with $\mathrm{O}_{2}$ before setting the initial reaction pressure of $\mathrm{O}_{2}$ to $10 \mathrm{bar}$. Concerning the start-up procedure, it was performed with the $\mathrm{O}_{2}$ line opened, and as the $\mathrm{O}_{2}$ was consumed, it was replaced from the cylinder, which maintains the overall pressure constant. The stirring speed of reaction mixture was set to $1,500 \mathrm{rpm}$ in general and the reaction was performed at $150{ }^{\circ} \mathrm{C}$ for $4 \mathrm{~h}$ unless otherwise stated. At the end of the reaction, the solid catalyst was separated by centrifugation.

\section{Results and discussion}

Catalysts characterization

Thermal analysis

Thermogravimetric (TGA) analysis of uncalcined Au catalysts supported on different metal oxides (e.g., $\mathrm{MgO}$, $\mathrm{CaO}, \mathrm{ZrO}_{2}, \mathrm{TiO}_{2}, \mathrm{Al}_{2} \mathrm{O}_{3}$, etc.) are presented in Fig. 1a. It is clear from the figure that the stability of Au catalyst is depended on the nature of the supports used. It should be noted that the precursors of $\mathrm{MgO}$ and $\mathrm{CaO}$ are $\mathrm{Mg}(\mathrm{OH})_{2}$ and $\mathrm{Ca}(\mathrm{OH})_{2}$. All studied catalysts have shown that the weight loss mainly occurs in two stages. First stage occurred in the temperature range from r.t. to $150{ }^{\circ} \mathrm{C}$, which is due to the loss of water molecules weakly bound to the material. Second stage observed between 150 and $350{ }^{\circ} \mathrm{C}$, seems to be due to dehydroxylation and also to the decomposition of reducing agents used. The weight loss observed on the whole temperature range from 5 to 

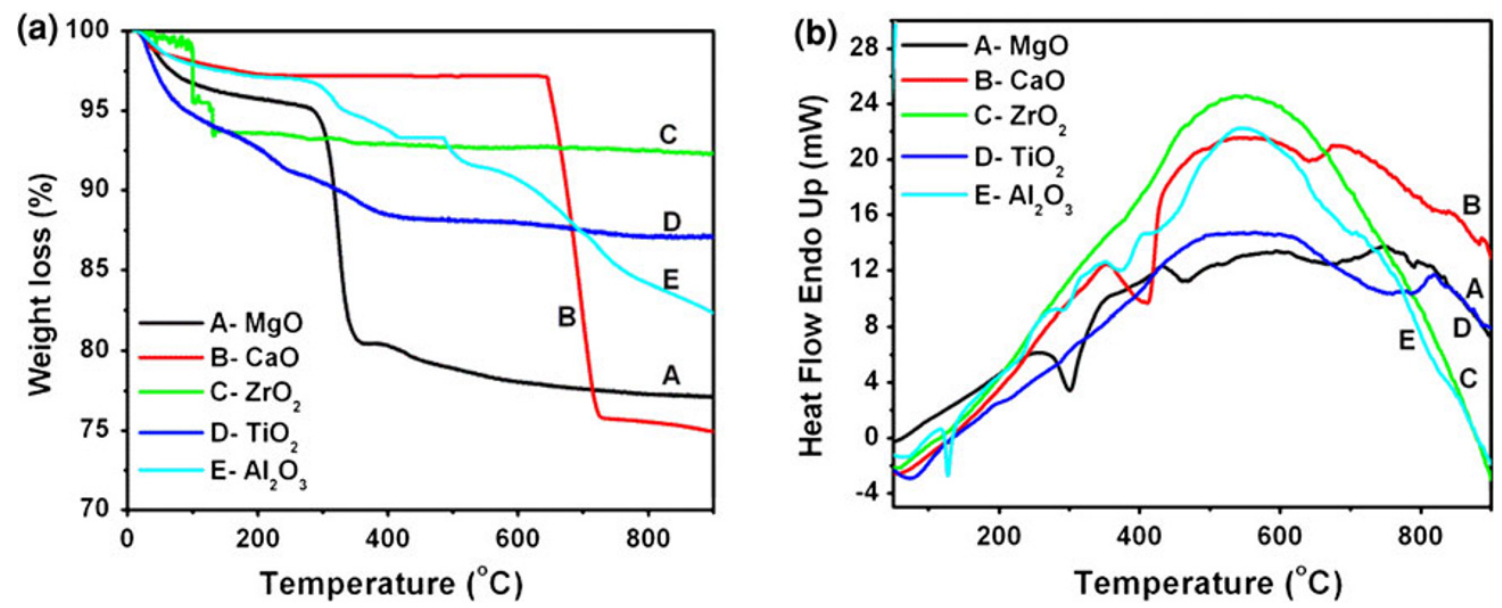

Fig. 1 TGA (a) and DTA (b) profiles of Au catalysts supported on different metal oxide carriers

$\sim 20 \%$, which however depends on the type of support used. Among all catalysts, alumina supported one is losing weight continuously with rise in temperature, while all others except $\mathrm{CaO}$ supported one showed only a marginal weight loss in the temperature range from 350 to $900{ }^{\circ} \mathrm{C}$. The sudden weight loss observed in case of $\mathrm{MgO}$ supported catalyst at around $330{ }^{\circ} \mathrm{C}$ can be attributed to the conversion of $\mathrm{Mg}(\mathrm{OH})_{2}$ into $\mathrm{MgO}$ [10]. Interestingly, $\mathrm{CaO}$ supported solid displayed quite stable behavior up to ca. $630{ }^{\circ} \mathrm{C}$ and then showed abruptly ca. $20 \%$ wt. loss at this temperature. This is undeniably due to transformation of $\mathrm{Ca}(\mathrm{OH})_{2}$ into $\mathrm{CaO}$. Holgado et al. (1992), also observed different stages of weight loss in case of $\mathrm{Ca}(\mathrm{OH})_{2}$ decomposition to $\mathrm{CaO}$, the first one at $323{ }^{\circ} \mathrm{C}$ ( $3 \%$ wt. loss) and the second one at $623{ }^{\circ} \mathrm{C}$ (wt. loss of $17 \%$ ) and the third one at $880{ }^{\circ} \mathrm{C}$ (wt. loss of $7 \%$ ). Our results are in good agreement with those reported by Hologado et al. [11]. In addition, AuNPs supported on reducible carriers (e.g., $\mathrm{ZrO}_{2}, \mathrm{TiO}_{2}$ ) are found to have the lowest weight loss in the whole temperature range among all investigated samples, which is about 6 and $11 \%$, respectively.

In addition, differential thermal analysis (DTA) patterns of the gold catalysts were also carried out, and the results are given in Fig. 1b. The initial weight loss observed by TGA for the all catalysts from 20 to $300{ }^{\circ} \mathrm{C}$ are also evidenced by a small endothermic transition in the DTA curve. Such endothermic effect is observed from 300 to $450{ }^{\circ} \mathrm{C}$ on the whole in almost all samples, which can be ascribed to the loss of water by dehydroxylation, decomposition of metal precursors to form oxides and also due to decomposition of organic reductants. Almost all catalysts, exhibited a broad exothermic peak in the range of 470 to ca. $700{ }^{\circ} \mathrm{C}$, which seems to be due phase transformation of supports (e.g., $\mathrm{TiO}_{2}$ (anatase) to $\mathrm{TiO}_{2}$ (rutile), monoclinic $\mathrm{ZrO}_{2}$ to tetragonal $\mathrm{ZrO}_{2}$, etc. It is also more likely that such exothermic peaks are due to the formation of metal oxide phase of the used support. XRD analysis of these also gave some supporting information on such assumption, which will be discussed later on.

\section{BET surface areas}

The specific surface areas and pore volumes of different pure supports and gold catalysts supported on different metal oxides are presented in Table 1. It is clear from the table that the surface areas and pore volumes are observed to change significantly by changing the nature of support materials. It is obvious that the surface area of most supports were drastically decreased after impregnation into the AuNPs. Nevertheless, for both $\mathrm{TiO}_{2}$ and $\mathrm{Al}_{2} \mathrm{O}_{3}$, an addition of AuNPs did not show a noticeable effect on the values of BET surface areas. These results indicate that the AuNPs are highly dispersed on the support without any sintering effect. Such good dispersion is also confirmed by XRD and TEM, which will be shown later.

\section{$X$-ray diffraction analysis}

The XRD patterns of the fresh Au catalysts are displayed in Fig. 2. Different oxide supports have been used such as

Table 1 BET-SA and pore volumes of gold catalysts on various oxide supports

\begin{tabular}{lllll}
\hline Entry & Catalyst & \multicolumn{2}{c}{ BET-SA $\left(\mathrm{m}^{2} / \mathrm{g}\right)$} & $\begin{array}{l}\text { Pore vol. of } \\
\text { cat. }\left(\mathrm{cm}^{3} / \mathrm{g}\right)\end{array}$ \\
\cline { 3 - 4 } & & Pure support & Catalyst & \\
\hline 1 & $\mathrm{Au} / \mathrm{MgO}$ & 59 & 34 & 0.09 \\
2 & $\mathrm{Au} / \mathrm{CaO}$ & 37 & 27 & 0.07 \\
3 & $\mathrm{Au} / \mathrm{ZrO}_{2}$ & 53 & 39 & 0.1 \\
4 & $\mathrm{Au} / \mathrm{TiO}_{2}$ & 47 & 43 & 0.12 \\
5 & $\mathrm{Au} / \mathrm{Al}_{2} \mathrm{O}_{3}$ & 265 & 261 & 0.80 \\
\hline
\end{tabular}




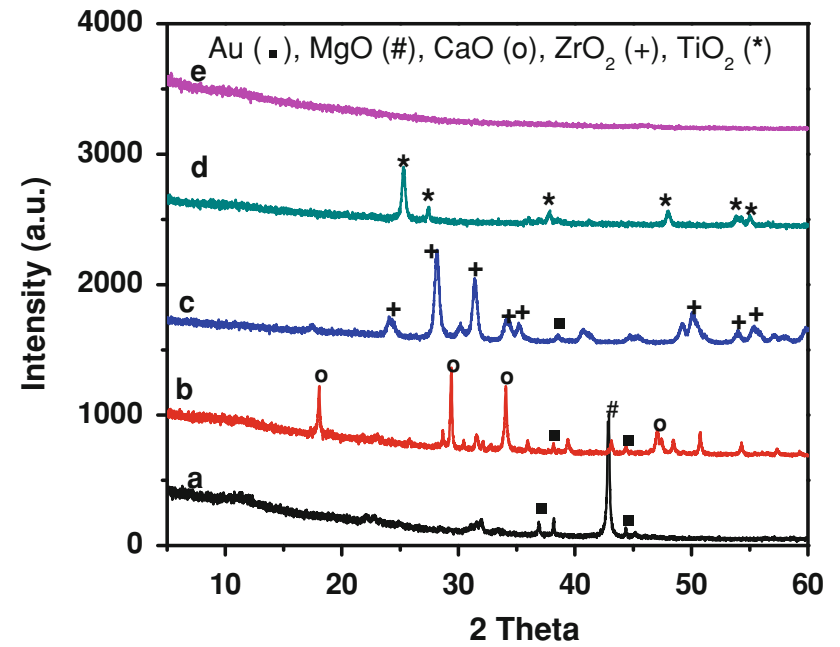

Fig. 2 XRD patterns of fresh $1 \% \mathrm{Au}$ catalysts with different supports $\mathrm{A}-\left(a \mathrm{MgO}, b \mathrm{CaO}, c \mathrm{ZrO}_{2}, d \mathrm{TiO}_{2}\right.$, and $\left.e \mathrm{Al}_{2} \mathrm{O}_{3}\right)$

Table 2 Binding energy and the surface atomic ratio of supported gold catalysts

\begin{tabular}{|c|c|c|c|c|c|}
\hline \multirow[t]{2}{*}{ Catalyst } & \multicolumn{4}{|c|}{ Binding energy $(\mathrm{eV})$} & \multirow{2}{*}{$\begin{array}{l}\mathrm{Au} / \mathrm{M} \text { atomic ratio } \\
\mathrm{Au}\end{array}$} \\
\hline & $\mathrm{Au}\left(4 \mathrm{f}_{7 / 2}, 4 \mathrm{f}_{5 / 2}\right)$ & M & $\mathrm{O}$ & $\mathrm{C}$ & \\
\hline \multirow[t]{2}{*}{$\mathrm{Au} / \mathrm{MgO}$} & 83.3 & 458.8 & 531.5 & 286.9 & \multirow{2}{*}{0.009} \\
\hline & 87.4 & 472.0 & 538.9 & 288.2 & \\
\hline \multirow[t]{2}{*}{$\mathrm{Au} / \mathrm{CaO}$} & 83.5 & 350.5 & 534.4 & 285.2 & \multirow{2}{*}{0.008} \\
\hline & 87.6 & & 538.7 & 287.4 & \\
\hline \multirow[t]{2}{*}{$\mathrm{Au} / \mathrm{ZrO}_{2}$} & 83.6 & 182.2 & 529.8 & 285.3 & \multirow{2}{*}{0.011} \\
\hline & 87.6 & 184.9 & 531.2 & 289.1 & \\
\hline \multirow[t]{2}{*}{$\mathrm{Au} / \mathrm{TiO}_{2}$} & 83.4 & 458.9 & 529.9 & 285.7 & \multirow{2}{*}{0.016} \\
\hline & 87.6 & 472.0 & 532.5 & 289.2 & \\
\hline \multirow[t]{2}{*}{$\mathrm{Au} / \mathrm{Al}_{2} \mathrm{O}_{3}$} & 83.7 & 74.5 & 523.3 & 285.4 & \multirow{2}{*}{0.012} \\
\hline & 87.6 & & 531.1 & 288.3 & \\
\hline
\end{tabular}

$\mathrm{MgO}, \mathrm{CaO}, \mathrm{ZrO}_{2}, \mathrm{TiO}_{2}$, and $\mathrm{Al}_{2} \mathrm{O}_{3}$. In general, the XRD pattern of $\mathrm{Au}$ shows the typical diffraction pattern of metallic $\mathrm{Au}$ by the presence of two diffraction lines one at $2 \theta=38.2^{\circ}(d=2.35 \AA)$ and the other at $2 \theta=43.4^{\circ}$ $\left(d=2.03 \AA\right.$ 趹. Among all studied catalysts, $\mathrm{Al}_{2} \mathrm{O}_{3}$ powder supported Au catalysts is found to be X-ray amorphous, which is in agreement with BET surface area data $\left(261 \mathrm{~m}^{2} / \mathrm{g}\right)$. The XRD of the fresh $\mathrm{Au} / \mathrm{TiO}_{2}$ sample also showed no patterns due to $\mathrm{Au}$, indicating that the gold particle size is less than $3 \mathrm{~nm}$ or Au has been doped into $\mathrm{TiO}_{2}$ lattice. This observation lent good support to the observations occurred by TEM that confirmed the size of $\mathrm{Au}$ found to be less than $3 \mathrm{~nm}$. However, the sample reveals reflections that corresponding to $\mathrm{TiO}_{2}$. In contrast, the XRD results of the $\mathrm{ZrO}_{2}$ supported Au catalysts showed that a weak reflections correspond $\mathrm{Au}$ phase besides the typical zirconia reflections (e.g., monoclinic phase). Moreover, gold catalysts supported on $\mathrm{MgO}$ and $\mathrm{CaO}$ exhibited the gold metal phases in addition to intense reflections that corresponding to $\mathrm{MgO}$ and $\mathrm{CaO}$. Hints on the formation of bigger AuNPs are also provided by TEM and SEM (not shown here).

\section{$X$-ray photoelectron spectroscopy}

The summary of XPS results such as binding energy (B.E.), atomic ratios obtained from supported gold catalysts are given in Table 2. It can be seen that the B.E. values of $\mathrm{Au}$ $4 \mathrm{f}_{7 / 2}$ and $4 \mathrm{f}_{5 / 2}$ spectral lines of $A u$ are varied over a narrow range from 83.3 to $83.7 \mathrm{eV}$, and 87.4 to $87.6 \mathrm{eV}$, respectively. These values clearly indicate that the gold in the catalysts is present mainly in metallic form, i.e., $\mathrm{Au}(0)$. This is good agreement with reported results in the literature $[12,13]$. The most striking feature here is the clear enrichment of $\mathrm{Au}$ in the near-surface-region particularly in the $\mathrm{Au} / \mathrm{TiO}_{2}$ solid compared to others as evidenced by the $\mathrm{Au} / \mathrm{metal}$ ratios. The values of spectral lines correspond to other components of the catalysts, e.g., supports, $\mathrm{O}$ as well as $\mathrm{C}$ are also summarized for better comparison in Table 2.

\section{TEM study}

TEM studies were used to explore such properties since the catalytic activity of gold catalyst is strongly depended on its particle size. It reported that the nature of the support can affect the size, morphology, and dispersion of Au particles
Fig. 3 TEM images of AuNPs supported on $\mathrm{TiO}_{2}$ and $\mathrm{Al}_{2} \mathrm{O}_{3}$
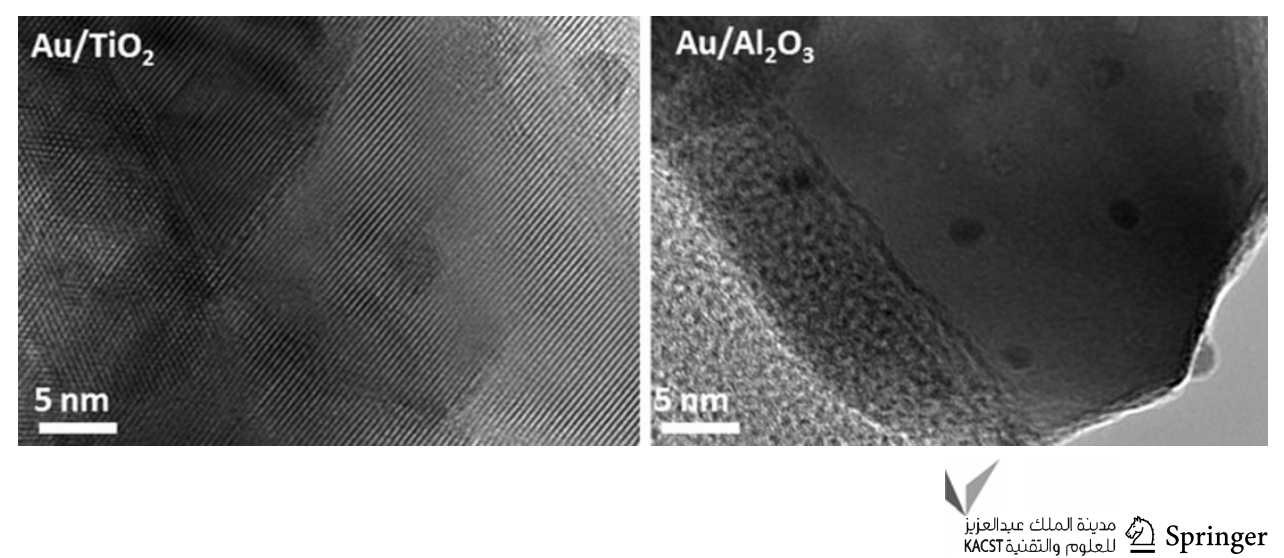
Fig. 4 HRTEM images of the AuNPs catalysts supported on $\mathrm{TiO}_{2}$ and $\mathrm{Al}_{2} \mathrm{O}_{3}$ carriers
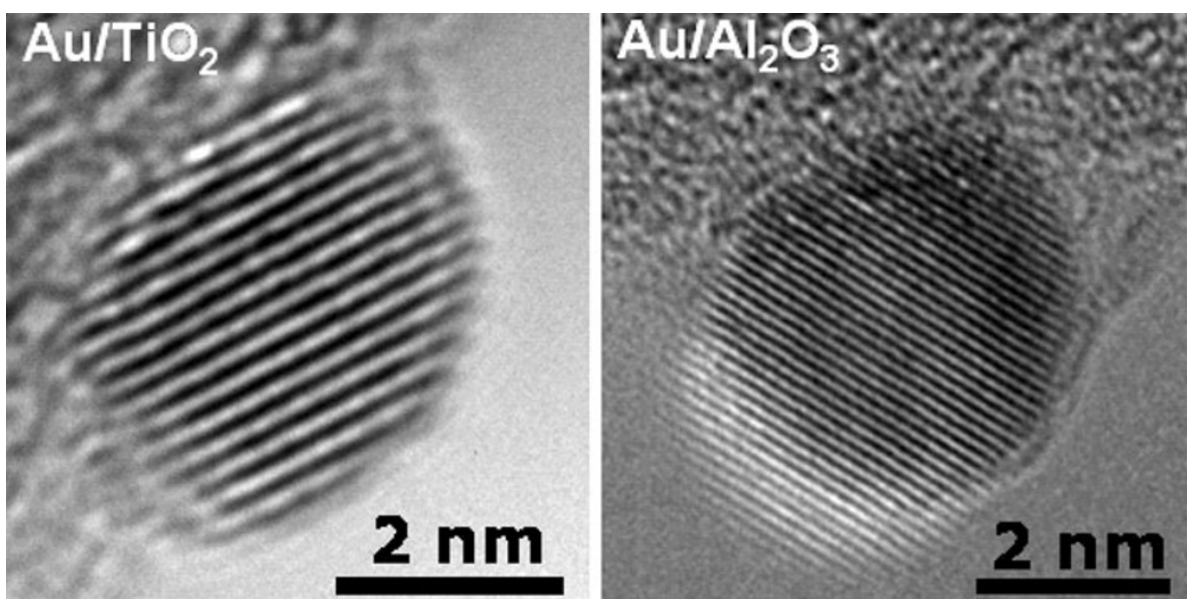

via metal-support interactions [14]. Representative of selected TEM images of Au catalysts supported on different metal oxides carriers (e.g., $\mathrm{TiO}_{2}, \mathrm{Al}_{2} \mathrm{O}_{3}$ ) are presented in Fig. 3. It is obvious that the resulting $\mathrm{Au}$ particles show almost spherical shape dispersed on the supports and the nature of support has considerable influence on the particle size. Among all catalysts, $\mathrm{TiO}_{2}$ and $\mathrm{Al}_{2} \mathrm{O}_{3}$ carriers found to give particles size with a narrow size distribution in the range from 1 to $5 \mathrm{~nm}$. However, in case of non-reducible supports (e.g., $\mathrm{MgO}, \mathrm{CaO}$, not shown here), there is a considerable increase in the $\mathrm{Au}$ particles, which varies in the range from 1 to $10 \mathrm{~nm}$, while the morphology of the particles remained unaltered. The sequence of increasing mean $\mathrm{Au}$ particle size for the gold catalysts supported on different carriers are $\mathrm{Au} / \mathrm{TiO}_{2}<\mathrm{Au} / \mathrm{Al}_{2} \mathrm{O}_{3}<\mathrm{Au} / \mathrm{ZrO}_{2}<\mathrm{Au} / \mathrm{CaO}<$ $\mathrm{Au} / \mathrm{MgO}$, suggests a dependency on the reducibility of the carrier. Nevertheless, in terms of activity, $\mathrm{Au} / \mathrm{TiO}_{2}$ and $\mathrm{Au} /$ $\mathrm{Al}_{2} \mathrm{O}_{3}$ are found to be the best catalysts. Therefore, these supports are much considered in our discussion.

\section{High-resolution TEM}

In order to control the nanocrystal shape of $\mathrm{Au}$ and further to understand the growth mechanism, high-resolution TEM (HRTEM) was performed. This technique has provided us information regarding the nature of the crystal faces. HRTEM images of AuNPs supported on $\mathrm{TiO}_{2}$ and $\mathrm{Al}_{2} \mathrm{O}_{3}$ are selected as examples and shown in Fig. 4. These images obviously revealed that the metal particles are almost spherical and most of them are highly diffused into the matrix of the both supports. However, some of them are also located on the surface of the support. From HRTEM image of AuNPs supported on $\mathrm{Au} / \mathrm{TiO}_{2}$ and $\mathrm{Au} / \mathrm{Al}_{2} \mathrm{O}_{3}$ solids, one can clearly observe the crystal planes of $\mathrm{Au}$. The lattice plane fringes of the AuNPs are used to calculate the $d$-spacing values, and were compared with those of bulk $\mathrm{Au}$ (the values in Tables 3 and 4 correspond to images of $\mathrm{Au} / \mathrm{TiO}_{2}$ and $\mathrm{Au} / \mathrm{Al}_{2} \mathrm{O}_{3}$ of Fig. 4), indicating the
Table 3 The inter planar spacing and diffraction planes of AuNPs supported on $\mathrm{TiO}_{2}$ carrier

\begin{tabular}{lll}
\hline $\begin{array}{l}d \text {-spacing calculated } \\
\text { from HRTEM }(\AA)\end{array}$ & $\begin{array}{l}d \text {-spacing in } \\
\text { bulk Au }(\AA)\end{array}$ & $\begin{array}{l}\text { Miller indices } \\
(h k l) \text { assignment }\end{array}$ \\
\hline 2.35 & 2.35 & 111 \\
2.06 & 2.04 & 200 \\
1.43 & 1.44 & 220 \\
1.18 & 1.17 & 222 \\
\hline
\end{tabular}

Table 4 The interplanar spacing and diffraction planes of AuNPs supported on $\mathrm{Al}_{2} \mathrm{O}_{3}$ carrier

\begin{tabular}{lll}
\hline $\begin{array}{l}d \text {-spacing calculated } \\
\text { from HRTEM }(\AA)\end{array}$ & $\begin{array}{l}d \text {-spacing in } \\
\text { bulk Au }(\AA)\end{array}$ & $\begin{array}{l}\text { Miller indices } \\
(h k l) \text { assignment }\end{array}$ \\
\hline 2.38 & 2.35 & 111 \\
1.41 & 1.44 & 220 \\
1.16 & 1.17 & 222 \\
\hline
\end{tabular}

formation of $\mathrm{Au}$ nanocrystals with spherical lattice. These results confirmed that precursor of $\mathrm{HAuCl}_{4}$ was reduced to $\mathrm{Au}^{0}$.

\section{Catalysts evolution}

Prior to perform the catalytic tests, some blank tests were carried out initially under similar conditions as that of real tests to determine whether the oxidation of $\mathrm{CH}$ can occur in the absence of catalyst and/or TBHP, in particular according to a radical mechanism. Such blank tests (in the absence of catalyst but in the presence of TBHP, and also in the absence of both TBHP and catalyst) showed almost negligible $\mathrm{CH}$ conversion of only $\sim 2 \%$ after $4 \mathrm{~h}$ of reaction and no AA was found in the product stream. This result clearly implies that (1) no significant reaction takes place under the conditions applied and (2) the nature of catalyst plays a key role on the performance. The influence 


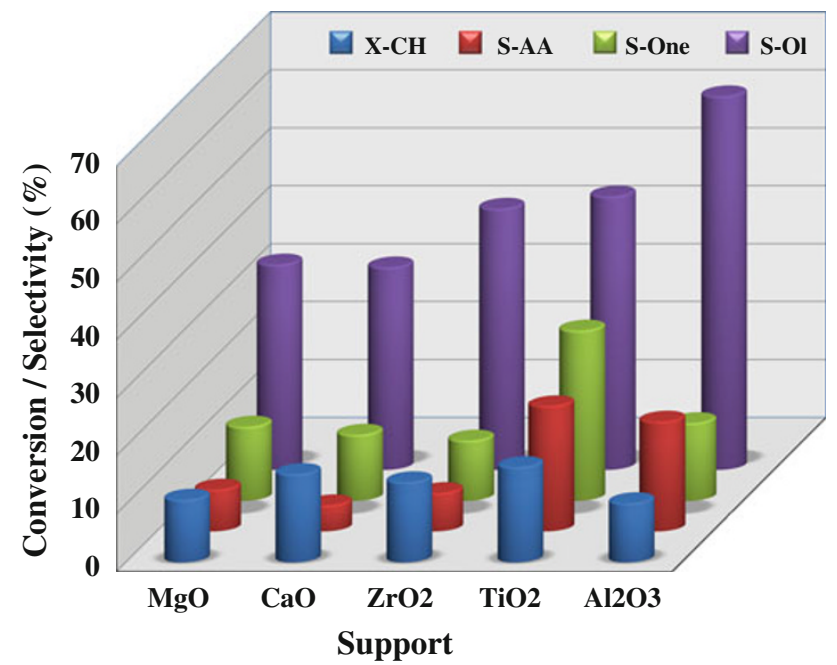

Fig. 5 Effect of support on the oxidation of cyclohexane $(\mathrm{CH})$ over AuNPs/SU catalysts $\left(\mathrm{SU}=\mathrm{MgO}, \mathrm{CaO}, \mathrm{ZrO}_{2}, \mathrm{TiO}_{2}, \mathrm{Al}_{2} \mathrm{O}_{3}\right), \mathrm{X}-\mathrm{CH}$, conversion of cyclohexane; S-AA, selectivity to adipic acid; S-One, selectivity to cyclohexanone; S-Ol, selectivity to cyclohexanol

of oxide supports on the oxidation activity of $\mathrm{CH}$ to AA is presented in Fig 5. It is obvious that the nature of support has a significant influence on the conversion of $\mathrm{CH}$ as well as the selectivity of products. $\mathrm{TiO}_{2}$ supported AuNPs exhibited the superior activity compared to all other catalysts. In addition, these results provide further evidence that the smaller size of Au particle is necessary and is also a crucial parameter for improving the performance of the catalysts. Again in this case, the $\mathrm{MgO} \& \mathrm{CaO}$ supported catalysts gave the poorest performance. Over these two catalysts, the highest amount of undesired side-products such as $\mathrm{CO}$ and $\mathrm{CO}_{2}(\mathrm{~S}=$ up to $35 \%)$ is observed. Therefore, it can be stated that $\mathrm{MgO}$ and $\mathrm{CaO}$ are not really suitable supports for this reaction. The conversion of $\mathrm{CH}$ and the selectivity of AA obtained over $\mathrm{TiO}_{2}$ supported catalyst is $16.4 \%$ and ca. $21.6 \%$, respectively [15]. Several efforts were also made in the literature by different research groups to used gold-based catalysts for the direct oxidation of cyclohexane to adipic acid, but not even $1 \%$ yield of adipic acid could be achieved from those investigations.

\section{Conclusions}

In this study, AuNPs supported on $\mathrm{TiO}_{2}$ was determined to be an optimum catalyst for the direct oxidation of cyclohexane to adipic acid. We have also proved that the size of $\mathrm{Au}$ plays a key role on the catalytic performance. In particular, it is proved that the production of adipic acid with $8 \%$ yield through the one-pot oxidation of cyclohexane is indeed a remarkable achievement of this study, with reasonable catalyst stability.

Acknowledgments The authors gratefully thank King Abdulaziz City for Science and Technology (KACST) for financing this work. The authors would also like to thank M. Ababtain (KACST) for TEM analysis and Schneider and Radnik (LIKAT) for solid analyses.

Open Access This article is distributed under the terms of the Creative Commons Attribution License which permits any use, distribution, and reproduction in any medium, provided the original author(s) and the source are credited.

\section{References}

1. Castellan A (1991) Industrial production and use of adipic acid. Catal Today 9:237-254

2. Schuchardt U, Cardoso D, Sercheli R, Pereira R, Cruz RS, Guerreiro MC, Mandelli D, Spinace EV, Pires EL (2001) Cyclohexane oxidation continues to be a challenge. Appl Catal A Gen 211:1-17

3. Horn HJ, Holland EG, Hazleton LW (1957) Safety of adipic acid as compared with citric and tartaric acid. Agric Food Chem 5:759-762

4. Roew R (2009) Adipic acid: handbook of pharmaceutical excipients, Pharmaceutical Press, London, pp 11-12

5. Sheldon RA, Kochi JK (1981) Metal-catalyzed oxidations of organic compounds. Academic Press, New York

6. Saji PV, Ratnasamy C, Gopinathan S (2002) Process for the oxidation of cyclohexane to adipic acid. U.S. Patent 6,392,093, B1

7. Starzyk FT (1994) Oxidation of cyclohexanone and cyclohexane to adipic acid by iron-phthalocyanine on zeolite Y. Stud Surf Sci Catal 84:1419-1424

8. Lu G, Zhao R, Qian G, Qi Y, Wang X, Suo J (2004) A highly efficient catalyst Au/MCM-41 for selective oxidation cyclohexane using oxygen. Catal Lett 97:115-118

9. Xie J, Wang Y, Li Y, Wei Y (2011) Self-assembly preparation of $\mathrm{Au} / \mathrm{SiO}_{2}$ catalyst and its catalysis for cyclohexane oxidation with air. Reac Kinet Mech Catal 102:143-154

10. Lee MH, Park DG (2003) Preparation of $\mathrm{MgO}$ with high surface area, and modification of its pore characteristics. Bull Korean Chem Soc 24:1437-1452

11. Hologado MJ, Rives V, Román SS (1992) Thermal decomposition of $\mathrm{Ca}(\mathrm{OH})_{2}$ from acetylene manufacturing: a route to supports for methane oxidative coupling catalysts. J Mater Sci Lett 11:1708-1710

12. Hutchings GJ, Hall MS, Carley AF, Landon P, Solsona BE, Kiely CJ, Herzing A, Makkee M, Moulijn JA, Overweg A, FierroGonzalez JC, Guzman J, Gates BC (2006) Role of gold cations in the oxidation of carbon monoxide catalyzed by iron oxide-supported gold. J Catal 242(1):71-81

13. Schimpf S, Lucas M, Mohr C, Rodemerck U, Brückner A, Radnic J, Hofmeister H, Claus P (2002) Supported gold nanoparticles: indepth catalyst characterization and application in hydrogenation and oxidation reactions. Catal Today 72:63-78

14. Bond GC (1997) Characterization of solid catalysts. In: Ertl G, Knoezinger H, Weitkamp J (eds) Handbook of heterogeneous catalysis, vol 2. VCH, Weinheim, p 752

15. Alshammari A, Köckritz A, Kalevaru VN, Martin A (2012) Method for catalyst preparation and its use in the oxidation of saturated hydrocarbons to carboxylic acids. US Patent 13/269,988, A1 